\title{
Publisher's Note: Universal pulse dependence of the low-energy structure in strong-field ionization
} [Phys. Rev. A 93, 021403(R) (2016)]

\author{
Kaikai Zhang, Yu Hang Lai, Elias Diesen, Bruno E. Schmidt, Cosmin I. Blaga, Junliang Xu, Timothy T. Gorman, \\ François Légaré, Ulf Saalmann, Pierre Agostini, Jan M. Rost, and Louis F. DiMauro
}

(Received 18 February 2016; published 4 March 2016)

DOI: 10.1103/PhysRevA.93.039902

This paper was published online on 17 February 2016 with a misspelling in the author list. The eighth author's name should read as "François Légaré." The author's name has been corrected as of 18 February 2016. The author's name is correct in the printed version of the journal. 